15 Newgreen, D. F., and Thiery, J. P., Cell Tiss. Res. 211 (1980) 269.

16 Perris, R., von Boxberg, Y., and Lofberg, J., Science 241 (1988) 86.

17 Rogers, S. L., Letourneau, P. C., Palm, S. L., McCarthy, J., and Furcht, L. T., Devl Biol. 98 (1983) 212.

18 Rogers, S. L., Edson, K. J., Letourneau, P. C., and McLoon, S. C., Devl Biol. 113 (1986) 429

19 Rogers, S. L., Letourneau, P. C., and Pech, I. V., Dev. Neurosci. 11 (1989) 248.

20 Ruoslathi, E., A. Rev, Biochem. 57 (1988) 375.

21 Sanes, J. R., A. Rev. Neurosci. 12 (1989) 491.

22 Simonneau, M., Distasi, C., Tauc, L., and Poujeol, C., J. Physiol., Paris 80 (1985) 312.
23 Spitzer, N., Trends Neurosci. 4 (1981) 169.

24 Tarone, G., Amedeo, M. R., and Comoglio, P., Exp. Cell Biol. 52 (1984) 225.

25 Tolosano, E., Distasi, C., Fiorini, F., Lovisolo, D., and Fasolo, A., Eur. J. cell. Biol, 49, suppl. 28 (1989) 53

26 Ziller, C., Dupin, E., Brazeau, P., Paulin, D., and Le Douarin, N. M., Cell 32 (1983) 627

$0014-4754 / 92 / 090859-06 \$ 1.50+0.20 / 0$

(C) Birkhäuser Verlag Basel, 1992

\title{
Serially arranged myofibers: An unappreciated variant in muscle architecture
}

\author{
A. S. Gaunt ${ }^{\mathrm{a}}$ and C. Gans
}

${ }^{a}$ Department of Zoology, The Ohio State University, 1735 Neil Avenue, Columbus (Ohio 43210-1293, USA), and Department of Biology, The University of Michigan, Ann Arbor (Michigan 48109, USA)

Received 26 November 1991; accepted 27 April 1992

Abstract. Our comparative studies suggest that the length of myofibers in tetrapods is subject to an unappreciated degree of variability. Many mammalian strap muscles are composed of short, overlapping myofibers. This arrangement and its associated distribution pattern of motor endplates (neural control) appear to be general in birds and widespread in other tetrapods. Contrariwise, most muscles of primates appear to be composed of long myofibers. The implications of this variation for studies of development, neuromuscular control, and muscle function are largely unexplored.

Key words. Birds; motor endplate; muscle: muscle architecture; pectoralis; myofiber.

Recent studies of muscle architecture have produced data concerning myofiber length that in some ways appear contradictory. The data are further confused by conflicting statements in the literature. Textbooks ${ }^{1-3}$ often directly state or strongly imply that the myofibers of parallel-fibered strap muscles in vertebrates run the full length of the muscle. However, there is an extensive physiological, neurological, and anatomical literature, dating back more than a century, that indicates that the myofibers of some mammalian strap muscles do not traverse the muscle, or even its fascicles. Rather, the myofibers are short, serially arranged fibers that overlap broadly. The intrafascicular ends of these fibers are tapered for about $30 \%$ of the fiber's length ${ }^{4-12}$. The axons of motor neurons innervating these myofibers branch to cells in each level or tier of the series. Motor endplates (meps) occur in zones or bands oriented perpendicularly to the columns of cells. These bands are revealed by staining for the acetylcholinesterase present in the endplates.

Although the existence of serially arranged muscles containing short fibers is well documented, many investigators appear to be unaware of the phenomenon. Hence, from time-to-time it is 'rediscovered'. A recent revival ${ }^{9}$ spurred a series of investigations that together have shown that: 1) Serially arranged fibers are generally missing in species of mammals in which strap muscles are $3 \mathrm{~cm}$ or less. 2) Myofibers in strap muscles of the hind leg of many medium-sized (cat ${ }^{9,13}$, goat ${ }^{11,13}$, pig ${ }^{14}$ ) to large (cattle ${ }^{14}$, giraffe and hippopotamus, pers. comm.) mammals are serially arranged, as are those of the thigh muscles of chickens ${ }^{15} .3$ ) The number and relative spacing of mep bands in any given muscle is established at birth ${ }^{11,14-16}$. 4) There are no specialized junctions between myofibers, but cells are bound together by a complex weave of collagen fibers. When a cell contracts, the tension generated is dispersed to and through both the collagen fibers and adjacent, non-contracting cells. The transfer of tension from contracting to non-contracting cells is aided by complex changes in the shape of the contracting cell. These changes help maintain a constant surface area ${ }^{17}$. Therefore, misunderstandings may result if a muscle is thought of as a scaled up sarcomere or as a series of sarcomeres with direct, linear transmission of tension along the series.

Most vertebrate twitch fibers are singly innervated ${ }^{8,18}$. If all cells extend the length of the muscle, and if all are innervated centrally, then one would expect to see a single band of meps more-or-less at the midlength of the muscle. Such a pattern is common in the strap muscles of many small mammals and in primates of all sizes. The presence of many mep bands along the length of a muscle might be explained by either of two possibilities. Long cells might be innervated at different points along their lengths. Alternatively, the muscle might be comprised of 
columns of short, serially arranged fibers, with successive mep bands innervating the fibers of successive levels in the series. This possibility raises the question of whether the mep pattern reflects myofiber number.

Studies of Japanese quail (Coturnix $c$. japonica) show that each fiber from the pectoralis has only one mep that usually occurs in the fiber's central $20 \%$. Each cell crosses 3-4 of the approximate 13 bands along a column of cells and overlaps cells of other levels for about $80 \%$ of its length ${ }^{18}$. Our observations of individual myofibers from several other species agree with these findings. Although the presence of numerous bands along a muscle does indicate the presence of short, serially arranged fibers, the interband interval is only an indirect measure of fiber length. The relationship of mep bands to fiber length and distribution is complicated by the degree of overlap between cells and the number of banding zones crossed by the cells. Further, that relationship may vary among muscles.

Our earlier studies of chickens suggested that the mep patterns of avian and mammalian muscles differ. Most avian muscles are multibanded, regardless of the size of the muscle or of the bird. Hence, we decided to undertake a comparative study of an avian muscle and an exploration of the literature. Our findings reveal not only greater variation among taxa than we had expected, but an unsuspected pattern to that variation. We here present an initial report of the pattern of mep banding in the avian pectoralis and compare those findings with our own experiences with mammalian tissue and reports from the literature.

\section{Materials and methods}

We chose the pectoralis for detailed examination because the number, size and arrangement of leg muscles vary among the taxa of birds, but the pectoralis has a relatively constant configuration. Further, the avian sternum is readily removed with the pectoralis intact, so that the muscle remains attached to a rigid frame that reduces problems of shrinkage or differential contraction. We examined the mep band pattern in the pectoralis muscles from 121 adult specimens of 48 species of birds ranging in size from blackchinned hummingbird (Archilochus alexandri, $2.8 \mathrm{~g}$ ) and golden-crowned kinglet (Regulus calendual, $6.0 \mathrm{~g}$ ) to sandhill crane (Grus canadensis, $5500 \mathrm{~g}$ ) and domestic turkey (Meleagris gallopavo, $17273 \mathrm{~g}$ ). The sample contained both sedentary and migratory species with many flying styles.

A few wild birds were collected directly (ASG Federal Scientific Collecting permit No. PRT-692176, Ohio permit No. 023), but most were obtained from road, window, and weather kills, or were carcasses provided by the research programs of colleagues or by organizations active in wildlife rehabilitation or monitoring diseases of wildlife. Freshly killed poultry were obtained from the Department of Poultry Sciences at The Ohio State University. Some techniques were tested using packaged cooking chickens purchased at a local supermarket, but such specimens are not included in the present analysis. Because the mep distribution in hummingbird pectoralis is unique (fig. 1), and because the y-intercepts of allometric curves for many measures related to metabolism differ between passerines and all other birds ${ }^{19}$, species were grouped as Hummingbirds, Passerines, or Non-passerines (except Hummingbirds). We also examined the supracoracoideus and some leg muscles in several species. The supracoracoideus is the antagonist of the pectoralis

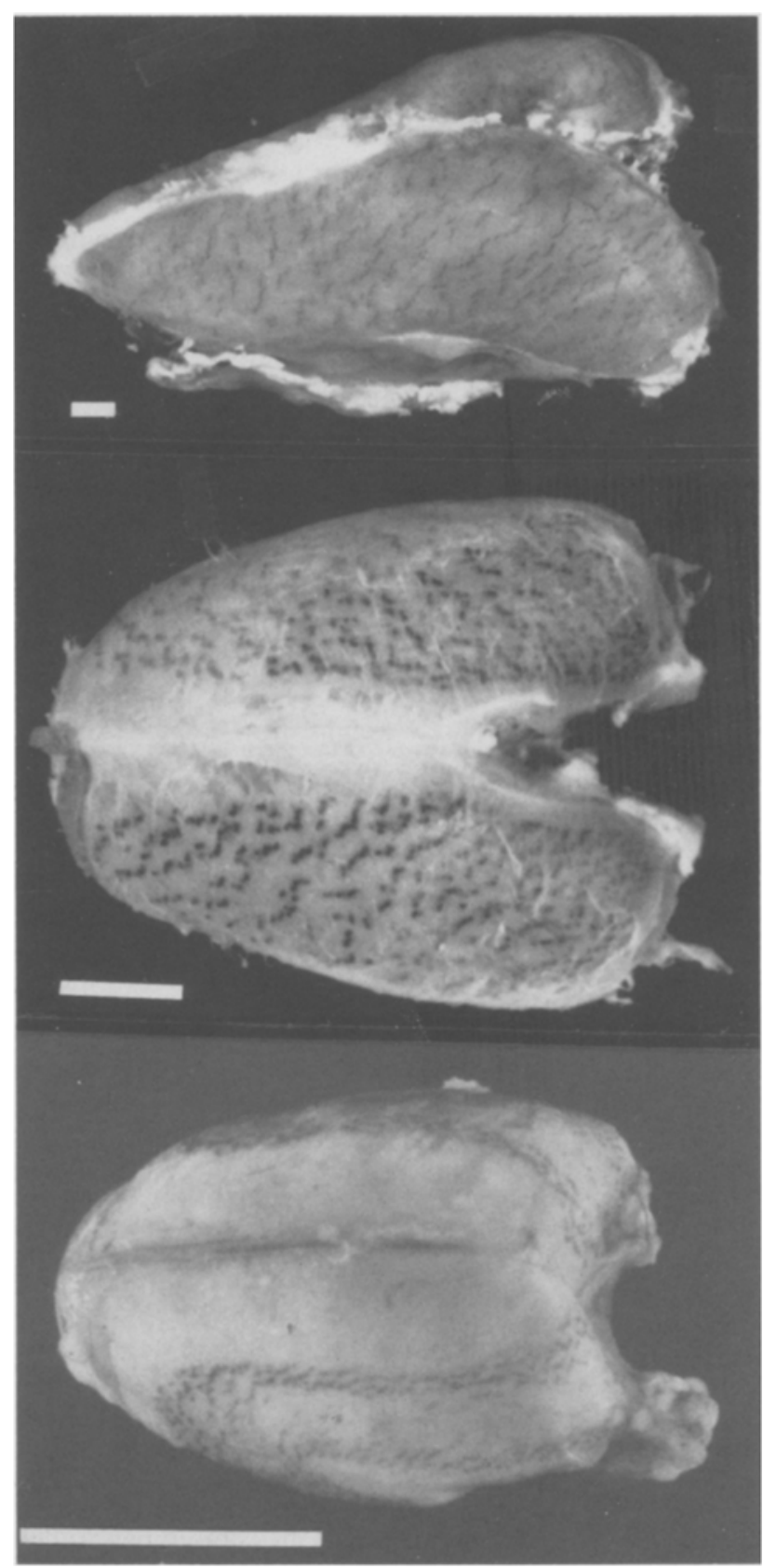

Figure 1. Pectoralis muscles of three birds stained to reveal motor endpiates. Scale bar in lower left of each frame $=1 \mathrm{~cm}$. Top: chicken; middle: cowbird; bottom: hummingbird. 
Table 1. Linear regression values for various measures for all specimens and for the median values of all species. The first character of each pair (Y) is regressed on the second $(\mathrm{X}) ; \mathrm{df}=$ degrees of freedom $(\mathrm{N}-2) ; \mathrm{r}^{2}=$ the square of the correlation coefficient and is a measure of the percent of the variation in $\mathrm{Y}$ that is attributable to variation in $\mathrm{X}$; $\mathrm{a}$ and $\mathrm{b}$ are from the regression equation $\mathrm{Y}=\mathrm{a}+\mathrm{bX}$, with a $=$ the value of $\mathrm{Y}$ when $\mathrm{X}=0$ (in arithmetic scales) or when $X=1$ (in logarithmic scales) and $b=$ the slope of the regression line; ${ }^{*} p<0.5 ;{ }^{* *} p<0.01$.

\begin{tabular}{|c|c|c|c|c|c|c|c|c|}
\hline & & $\mathrm{r}^{2}$ & a & b & $\begin{array}{l}\text { Spe } \\
\text { df }\end{array}$ & $\mathrm{r}^{2}$ & a & $\mathrm{b}$ \\
\hline \multicolumn{9}{|c|}{ Column length: log body mass } \\
\hline Passerines & 51 & $70.7 \% * *$ & 1.18 & 16.35 & 20 & $75.9 \% * *$ & -1.38 & 18.20 \\
\hline Non-passerines & 24 & $77.0 / \% * *$ & -103.98 & 61.61 & 16 & $75.6 \% * *$ & -89.24 & 55.23 \\
\hline Both & 77 & $72.7 \% * *$ & -29.26 & 36.01 & 38 & $73,5 \% * *$ & -29.77 & 35.64 \\
\hline \multicolumn{9}{|c|}{ Column length: number of intervals } \\
\hline Passerines & 67 & $1.1 \%$ & 18.76 & 0.52 & 22 & $0.8 \%$ & 18.18 & 0.51 \\
\hline Non-passerines & 44 & $34.7 \% *$ & -107.26 & 12.62 & 17 & $54.5 \% * *$ & -166.56 & 16.76 \\
\hline \multicolumn{9}{|c|}{ Maximum interval length: column length } \\
\hline Passerines & 67 & $57.5 \% * *$ & -0.22 & 0.16 & 22 & $54.2 \% * *$ & 0.33 & 0.13 \\
\hline Non-passerines & 44 & $86.9 \% * *$ & 1.57 & 0.10 & 17 & $85.4 \% * *$ & 1.78 & 0.09 \\
\hline \multicolumn{9}{|c|}{ Mean interval length: column length } \\
\hline Passerines & 67 & $84.7 \% * *$ & 0.08 & 0.08 & 22 & $89.3 \% * *$ & 0.06 & 0.08 \\
\hline Non-passerines & 44 & $93.5 \% * *$ & 0.94 & 0.06 & 17 & $96.8 \% * *$ & 1.01 & 0.05 \\
\hline
\end{tabular}

and lies deep to that muscle. It has a classic bipinnate fiber arrangement.

The entire sternum and attached musculature were stained for meps using the technique of Karnovsky and Roots $^{20}$. Staining in situ reduced shrinkage. Bands were counted along a column of cells adjacent to a cutaneous nerve that emerges about midway between the shoulder and the sternal keel. Interband intervals were measured with digital calipers and automatically recorded. Because weight was available for only some specimens, and because thoracic shape varied among species (long and narrow to short and wide), length of the column of fibers is plotted as a measure of size. Linear regression of column length on log body weight shows these two measures to be closely related in all species except Hummingbirds (table 1). Because sample sizes differed (1-11), we compare the median values for each species.

\section{Results}

In the pectoralis of Passerines and Non-passerines, the entire length of a column of fibers is banded. The number of bands (intervals-1) in the 'nerve' column ranges from 9 to 18 (fig. 2). As in many leg muscles ${ }^{15}$, the interband interval varies along the column, being short proximally near the shoulder and longer near the middle of the column. In many species, the most distal interval was the longest, thereby providing a zone without end plates on either side of the keel (see Cowbird, fig. 1). Regressions of interval number vs column length show that a bird's size does not contribute importantly to the determination of mep band number for specimens or species of Passerines, but does have an effect in Non-passerines (table 1, fig. 2)

We also examined the relationship between column length and the number of bands in the column by arranging the samples according to increasing column length, then dividing each sample into Small, Medium and Large subsets. If the sample was not evenly divisable by three,
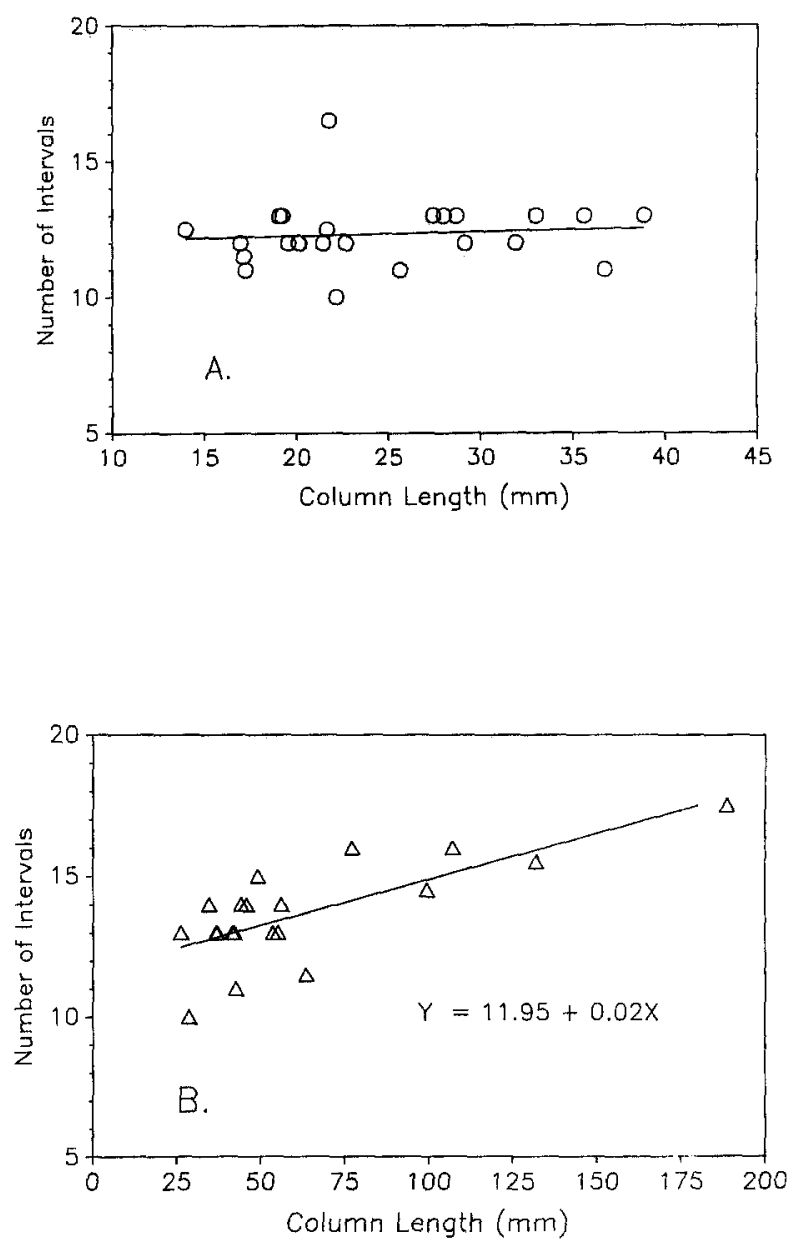

Figure 2. Regressions of interval number vs column length. The regression is of median values for species. $A$ Passerines. The regression is not significant. The outstanding point at 16.5 intervals represents two American goldfinches (Carduelis tristis). $B$ Non-passerines. This regression is highly significant with $\mathrm{p}<0.01$ that the points are random. Values for the inverse of this relationship, for which $\mathrm{r}^{2}$ is the same, are presented in table 1. The three points at the lower left represent, from left to right, a saw-whet owl (Aegolius acadicus), a ring-billed gull (Larus delawarensis), and two mallards (Anas platyrhynchos). These species share no obvious ecological or flight characteristics and range across two orders of magnitude in body mass. 
Table 2. Intervals (bands +1 ) per column in the smallest, middle and largest thirds of the samples. Extra specimens or species are included in the middle subsample. Number, range, and mean \pm 1 standard error

\begin{tabular}{|c|c|c|c|c|c|}
\hline \multirow{2}{*}{$\begin{array}{l}\text { Passerine specimens } \\
\text { Small }\end{array}$} & \multirow[b]{2}{*}{ Medium } & \multirow[b]{2}{*}{ Large } & \multicolumn{3}{|c|}{ Non-passerine specimens } \\
\hline & & & Small & Medium & Large \\
\hline $\begin{array}{l}23 ; 10-16 \\
12.5 \pm 0.2\end{array}$ & $\begin{array}{l}23 ; 10-17 \\
12.0 \pm 0.4\end{array}$ & $\begin{array}{l}23 ; 11-15 \\
12.7 \pm 0.3\end{array}$ & $\begin{array}{l}15 ; 10-15 \\
13.1 \pm 0.3\end{array}$ & $\begin{array}{l}16 ; 10-15 \\
13.1 \pm 0.3\end{array}$ & $\begin{array}{l}15 ; 12-19 \\
15.3 \pm 0.6\end{array}$ \\
\hline $\begin{array}{l}\text { Passerine species } \\
\text { Small }\end{array}$ & Medium & Large & $\begin{array}{l}\text { Non-passer } \\
\text { Small }\end{array}$ & Medium & Large \\
\hline $\begin{array}{l}8 ; 11-13 \\
12.2 \pm 0.2\end{array}$ & $\begin{array}{l}8 ; 10-17 \\
12.6 \pm 0.7\end{array}$ & $\begin{array}{l}8 ; 11-13 \\
12.5 \pm 0.7\end{array}$ & $\begin{array}{l}6 ; 10-14 \\
12.7 \pm 0.5\end{array}$ & $\begin{array}{l}8 ; 11-15 \\
13.4 \pm 0.4\end{array}$ & $\begin{array}{l}6 ; 11.5-17.5 \\
15.1 \pm 0.8\end{array}$ \\
\hline
\end{tabular}

the remainder specimens were assigned to the middle set. We then determined the mean number of intervals for each subset (table 2). The subsets of Passerine birds show no differences among the mean number of intervals per column, either for all specimens or for median values for species; nor are there clear trends. Among the Nonpasserines, the means for Small and Medium specimens are identical, but the mean for Large birds is clearly greater. The means for the subsets of Non-passerine species also show an increase with size, with a jump between the values for Medium and Large. An analysis of covariance shows significant differences among the means of the species subsets $(\mathrm{p}=0.012)$, but that all share a similar $Y$-intercept $(\mathrm{p}>0.85)$.

Hummingbirds differ from all of these. The relatively huge pectoralis of these tiny birds has three, closely spaced bands of meps forming a loop around its margins. The loop, thus, crosses each column of cells twice, once proximally, once distally. Some meps lie within the area enclosed by the loop, but none falls outside. Hence, the number of mep bands along any column ranges from 6 to 8 . Because of this unique arrangement, Hummingbirds cannot be compared with other birds and are excluded from our graphs.

With the possible exception of the gastrocnemius and other distal leg muscles, most avian muscles, whether strap or pinnate, have many mep bands. Even the tiny ( $<6 \mathrm{~mm}$ ) sartorius of a hummingbird's leg (used only for perching), has 5-6 bands. The relatively short columns of the bipinnate supracoracoideus are distinctly multibanded in all species. The ambiens, a muscle of the inner thigh, is odd in that it has two bands, one proximal on its medial surface, the other distal and on the lateral surface. The peroneus longus of the lower leg is reported to be single banded and to have myofibers that extend its length ${ }^{21}$.

\section{Discussion}

The distribution of meps in the avian pectoralis reflects much of what can be said about meps in avian muscles in general. The muscle is strongly multibanded, even in small species. Further, the effect of size is remarkably small, being essentially absent among passerine species and eliciting only a slight increase in the numbers of mep bands among all species with column lengths less than
$65 \mathrm{~mm}$ (a sample including birds with body weights of 6-1300 g). Passerine species are distributed over a much smaller size range $(6.3-103 \mathrm{~g}, 14-39 \mathrm{~mm}$ column length) than are Non-passerines (60-14990 g, 26-189 mm). Therefore, the range for Passerines may be too small to show any size effect. A more important factor is that, although only the three smallest Non-passerine species fall into the size range of the Passerines, 9 bands (10 intervals) is the minimum for both groups. Thus, small size is not associated with fewer cells or neuronal branches, but larger birds may have more of both. Evidently the system requires a minimum number of myofibers (or axonal branches), these increase in length with species size up to some maximum, whereupon additional bands are added.

Column length is the product of the number of intervals times interval length. Hence, if the number of intervals along the columns of a sample is a constant, then interval lengths for that sample will correlate absolutely with the column lengths. Similarly, if the number of bands varies regularly with column length, then the interval length will vary just as regularly, and if there is no regular relationship between interval number and column length, there can be no regular relationship between interval and column lengths. In both Passerines and Non-passerines, interval dimensions vary rather closely with column length, but the variation in interval numbers in Passerines is not related to size (table 1). This suggests that the number of bands in Passerines does not vary randomly, but around some constant, and this relationship is evident in figure $2 \mathrm{~A}$.

The maximum interval need not be tightly correlated with column length. Not only might it be determined by some factor other than column length, but if there is an upper limit to fiber length, then there should be a maximum interval length. Correlation of interval length to column length should then diminish with the addition of larger specimens. Our sample does not show this happening. Indeed, the regression of maximum interval length on column length is stronger for Non-passerines. The relationships among column length, fiber size, and interband interval in avian muscle appear to be ordered, but not simple.

Disparate statements in the mammalian literature concerning myofiber lengths reflect the fact that the mam- 
malian situation is not simple. The presence or absence of serially arranged fibers is not related solely to adult size. Even in rats and mice the gracilis and latissimus dorsi are multibanded and contain at least two cells in series ${ }^{8,22}$. If we consider variation in the opposite direction, the presence of truly long fibers in humans is well documented ${ }^{16,23-26}$. However, the human gracilis and sartorius are multibanded and contain relatively short cells. However, those 'short' cells are $7-18 \mathrm{~cm}$ long ${ }^{20}$. We have recently been able to examine the leg muscles of a baboon (Papio sp.) and a ring-tailed lemur (Lemur catta). Baboon muscles were architecturally similar to those of humans. The tissue from the lemur was in poor condition, but the mep pattern we were able to expose was similar to the other two primates.

The above patterns of variation suggest two things. First, factors determining the arrangements of fibers in mammalian and avian muscles are different. Spot checks of other taxa suggest that spacing of mep bands in the muscles of lizards ${ }^{27}$, crocodilians (pers. obs.), and some amphibians ${ }^{28}$ (pers. obs.) resemble those in birds. Thus, the mammalian abilities to vary fiber length with size and to produce relatively long fibers may be unique among vertebrates. Second, the facts that mammals show variation among the muscles of an individual and that the mammalian gracilis seems always to be multibanded suggest that myofiber length has some as yet undetermined functional value. This possibility is supported by the unique, unexplained, pattern of meps in the pectoralis of hummingbirds. Indeed, Otten ${ }^{29}$ has already shown that the length-force relationship is significantly affected by myofiber length. Variations in the number and arrangement of myofibers require corresponding revisions of motoraxon branching patterns. Thus, both motor-control capabilities and their development in birds and mammals may also differ.

These variations divide tetrapods into three groups (fig. 3): 1) bird-like animals, in which serially arrayed

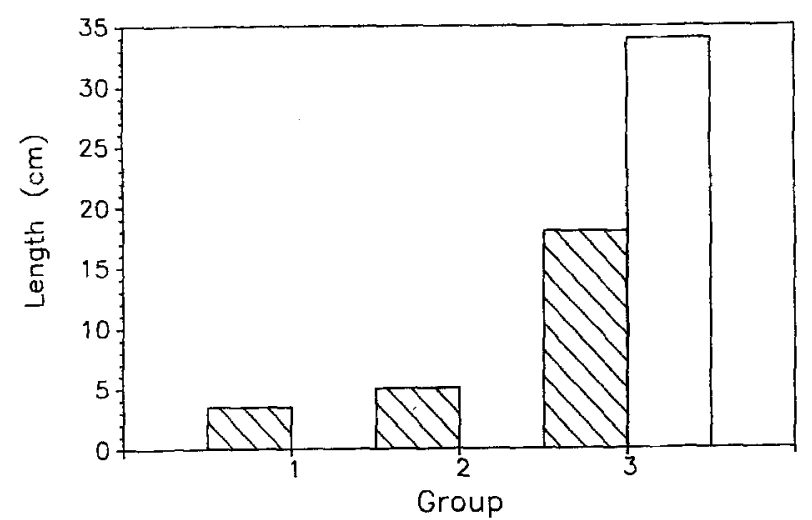

Figure 3. Maxirnum reported or observed lengths of myofibers. Values for multibanded muscles in hatched bars; continuously fibered muscles in open bar. Group 1, bird-like ${ }^{6}$; group 2, most mammals ${ }^{9,11}$; group 3, primates ${ }^{14,16}$. The $34-\mathrm{cm}$ myofiber reported for humans ${ }^{14}$ was a broken fiber. myofibers occur in most muscles, myofibers are less than $5 \mathrm{~cm}$ long, and interband intervals are conveniently measured in millimeters; 2) most mammals, in which the serial arrangement depends in part on adult muscle length, myofibers are less then $5 \mathrm{~cm}$, and interband intervals are measured in centimeters; and 3) primates, in which serially-fibered muscles are exceptional with most muscles having one central mep band, myofibers even in multibanded muscles may be $18 \mathrm{~cm}$ long, and interband intervals in multibanded muscles range to several centimeters. It is important to re-evaluate what parameters may be meaningfully compared among these groups.

Acknowledgments. This work was supported in part by a Challenge Grant from The Ohio State University Graduate School to ASG and funds from the Leo Leeser Foundation to CG. We thank Ohio Department of Natural Resources, Patuxent Wildlife Research Center, the O.S.U. Department of Poultry Science, the University of Michigan Museum of Natural History, and several colleagues for contributions of specimens. Drs John Trotter and Lewis Greenwald commented on an earlier version.

1 Fawcett, D. W., A Textbook of Histology. Saunders, Philadelphia 1986.

2 Hildebrand, M., Analysis of Vertebrate Structure, 3rd Edn. Wiley, New York 1988.

3 Schumacher, G. -H., Kompendium und Atlas der allgemeinen Anatomie mit Zytologie und Histologie. Thieme, Leipzig 1984.

4 Rollet, A., in: A Manual of Human Microscopic Anatomy. Ed. A. Kölliker. Parker and Son, London 1860.

5 Froriep, A., Arch. Anat. Entwges., Abt. Anat. 2 (1878) 416.

6 Huber, G. C., Anat. Rec. 11 (1916) 149.

7 Adrian, E. D., J. Physiol., London 60 (1925) 301

8 Schwarzacher, H. G., Acta anat. 30 (1957) 758.

9 Loeb, G. E., Pratt, C. A., Chanaud, C. M., and Richmond, F. J. R., J. Morphol. 191 (1987) 1.

10 Lev-tov, A., Pratt, C. A., and Burje, R. E. J., J. Neurophysiol. 59 (1988) 1128 .

11 Gans, C., Loeb, G. E., and De Vree, F., J. Morphol, 199 (1989) 287.

12 Gans, C., and Gaunt, A. S., J. Biomech. 24, Suppl. 1 (1991) 53.

13 Richmond, F. J. R., MacGillis, D. R., and Scott, D. A., J. Neurophysiol. 53 (1985) 868.

14 Swatland, H. J., and Cassens, R. G., J. Anim. Sei. 33 (1971) 750

15 Gaunt, A. S., and Gans, C., Proc. R. Soc. Lond. B 240 (1990) 351.

16 Christensen, D., Am. J. phys. Med. 38 (1959) 65.

17 Trotter, J. A., J. Morphol. 206 (1990) 351.

18 Trotter, J., Salgado, J. D., Ozbaysal, R., and Gaunt, A. S., J. Morphol. 212 (1992) 27

19 Norberg, U. M., in: Zoophysiology, vol. 27, Vertebrate Flight. Springer-Verlag, Berlin 1990.

20 Karnovsky, M. J., and Roots, L. J., Histochem. Cytochem. 12 (1964) 219.

21 Boesinger, B., Acta anat. 141 (1991) 109.

22 Wines, M. M., and Hall-Craggs, E. C. B., J. comp. Neurol. 249 (1986) 147.

23 Lockhardt, R. D., and Brandt, W., J. Anat. 72 (1937/38) 470.

24 Schwarzacker, H. G., Acta anat. 37 (1959) 217

25 Barrett, B., Acta anat. 48 (1962) 242.

26 Aquilonius, S-M., Håkan, A., Gilber, P.-G., Nandedkar, S., Olsson, Y, and Stålberg E., Muscle Nerve 7 (1984) 287.

27 Carrier, D. R., J. exp. Biol. 143 (1989) 435.

28 Assmussen, G., and Kiessling, A., Acta anat. 90 (1974) 226.

29 Otten, E., Exerc. Sport Sci. Rev. 16 (1988) 89.

$0014-4754 / 92 / 090864-05 \$ 1.50+0.20 / 0$

(C) Birkhäuser Verlag Basel, 1992 